\title{
TRENDS IN AUTOMOTIVE ELECTRONICS
}

\author{
Harikishnan E. \\ Department of Electrical and \\ Electronics Engineering \\ NSS College of Engineering \\ Palakkad, Kerala
}

\author{
Dr. Vasanthi V. \\ Department of Electrical and \\ Electronics Engineering \\ NSS College of Engineering \\ Palakkad, Kerala
}

\begin{abstract}
Since the invention of wheels' human mind is working hard to better his convenience in the field of conveyance. This has resulted in betterment of transmission system, fuel efficient engines and a host of other features. There was a time when the digital clock was the most sophisticated electronic part in an automobile. However, these days almost all modern cars have a sophisticated control cluster to control engine operation, braking system, temperature inside the vehicle and all the like. Besides this, various sensors, micro-controllers and even mini-computers are used in motor vehicles now-a-days for improved operating efficiency, emission control and safety. Since motor vehicles are becoming the prominent mode of conveyance the automobile industry will surely progress further taking mankind to a more connected and digitized setup. Now a day's electric vehicles are becoming more affordable with various multi-national companies unveiling hybrid cards suggesting that fuel efficiency will soon be adopted widely around the world. Machine learning and Artificial Intelligence will play a major role in the automotive industry in the near future as analytical capabilities are becoming more prevalent in cars personalizing the driving experience. Vehicles are becoming IoT devices which can be connected to devices like smart phones and can take voice commands through it. In view of all these it is imperative that automotive system designers familiarize themselves with the advantages of these type of control systems paving the way for more powerful vehicles with considerable fuel economy riding comfort and safety.
\end{abstract}

Keywords-Automotive control units, engine control, electronic fuel management, traction control, automatic transmission control, On-Board Information and Guidance System, Electronic climate control, Automotive Safety, Case study- TCCS.

\section{INTRODUCTION}

There was a time when the digital clock was the most sophisticated electronic part in an automobile. However, these days nearly all modern cars have a sophisticated electronic control module (ECM) which controls engine operation. The development from digital clock to ECM did not take place overnight, but was a result of sustained innovation by manufacturers of microelectronics and automobiles. The automotive electronics trend started in the sixties with the introduction of solid state radio. The next decade brought in solid state ignition modules and digital clocks. Then came electronic engine control system. However, it was only in the eighties that the use of automotive electronics became pervasive. Later in the nineties applications including systems for anti-lock braking, transmission control and emission control as well as luxury features such as compact disk (CD) players, automatic climate control and smart seats. Current applications include usage of power electronics circuits for regenerative braking, smart energy monitors and hybrid electric vehicles. The growing association of electronics with automobiles has opened up a huge market for such devices. It is estimated that the value of electronic components installed in cars will raise from U.S. $\$ 2000$ per car in 2019 to U.S. $\$ 5000$ by 2030 and perhaps U.S. $\$ 9500$ by the end of the century [4].

\section{Trends in Automotive Devices}

After the incredible success of electronics in improving automotive performance and operating features in the eighties and nineties the trend is likely to continue till the end of twenty first century. The fastest growth will be in the areas of chassis electronics and safety and convenience features. Entertainment and power train controls applications are likely to grow at around six percent per annum.

In early $21^{\text {st }}$ century automotive electronics will focus on the following factors:

- Improved operating features and conveniences.

- Improved emission control and safety.

- Improved manufacturability and reliability.

- Improved energy management.

These demands on automotive electronic have already been reflected in next generation IC design trends, viz the shift from 8 bit to 16 to 32-bit processing, networking, use of power ICs, advanced linear devices and the AS ICs. The different stages in the evolution of automotive electronics are as follows:

A. Year 1960-1970

- $\quad$ Solid state radio.

- Alternate rectifier.

- Speed control.

B. Year 1970-1980

- Electronic ignition.

- Digital clock.

- Electronic voltage regulator.

- Automotive electronic control units (ECUs) was introduced. 
- First generation ECM.

- Second generation ECM.

- Trip computer.

- Electronic instrument cluster.

C. Year 1980-1990

- Clock integrated with radio.

- Third generation ECM.

- Electronic climate control.

- Audio graphic equalizer.

- Fourth generation ECM.

- Electronic air suspension.

- CRT display with shared functions.

- Anti-Lock braking speed control integrated with engine control.

- Compact disk-players

- Hard-Soft suspension.

- Distributor-Less Ignition.

- Variable assist power steering.

- Transmission clutch, shift and pressure controls.

- Integrated engine control.

D. Year 1990-2000

- Electronically controlled torque vectoring differential.

- High-Tech headlamps.

- Smart keys.

- On-Board engine diagnostics.

- Bluetooth integration.

- Radar based cruise control.

- Crash detection and Airbags.

- Electronic stability control.

E. Year 2000-2010

- Electronic assist dual clutch transmission.

- Electronic tire pressure monitoring.

- Rear view backup camera.

- Electronic sun-roof.

- GPS Satellite navigation.

- Power steering.

- Power windows.

- Security alarms.

- Safety controls

F. Year 2010-2019

- Automatic headlamps.

- Automatic windshield wipers.

- Complex copper wire harness to high speed data cables.

- Collision avoidance system.

- Transmission control.

- AI Google car

\section{MAJOR TyPES OF SEMICONDUCTOR DEVICES FOR AUTOMOTIVE ELECTRONICS}

Major types of semiconductor devices for automotive electronics are:

\author{
i. Linear/Analogue devices. \\ ii. Microcontrollers. \\ iii. Digital Signal Processors (D. S. P.). \\ iv. Programmable memories.
}

\section{A. Linear/Analog Devices:}

One of the biggest demand segments among semiconductor components has been linear/analogue devices. Newer linear circuits are likely to be used extensively to help control engine functions, act s sensor in a variety of engine and power train control systems, systems and improve entertainment and convenience functions of the vehicle. Linear devices can also be used for level shifters, current, feedback and load diagnostics. Power linear devices are used for improved performance of control critical engine and transmission elements [1] such as fuel injectors and transmission actuators.

\section{B. Microcontrollers:}

Microcontrollers have been traditionall the most important device for automotive electronics. Initially, 8-bit microcontrollers held the sway; However, by ninties witnessed a widespead application of 16-bit and 32-bit microcontrollers. The anti-lock braking system (ABS), cruise control, engine and transmission controls and a host of other functions were desigined around these powerful microcontrollers. The level of integration and speed of single-chip microcontrollers improved by $120 \%$ in nineties. By the begining of the twentyfirst century conventional chips with $16 \mathrm{~KB}$ RAM and $512 \mathrm{~KB}$ ROM was substituted with higher end versions. Also clock frequency in use skyrocketed from $15 \mathrm{MHz}$ to $30 \mathrm{MHz}$.

\section{Digital Signal Processors: (D.S.P.)}

New applications in automotive industry are being designed around D.S.Ps. and in-cylinder pressure sensors make it possible to implement real time closed loop engine control. Thus, DSP approach can provide more accurate antiknock solutions with optimum timing control. DSP chips are an order of magnitude faster than standard controllers in their computational speed, which is the key to develop advance suspension system. As an example, only a high performance DSP has the capability to evaluate change in the position of each wheel, calculate the compensation required using sophisticated algorithms and adjust the position of the wheel to negate the effect of a bump, a dip or a turn.

\section{Programable Memories:}

Automotive electronics is moving from standard EPROMs to flash memories as Flash memories are nonvolatile and has abilities to hold data even without power. The ability to store critical data values during intermittent system failures or unusual operating condition is a useful diagnostic tool. Flash EEPROM devices can be used to store such exhaustive data. The next major step in programmable memories will be OTP (One time programmable) ROMs [2]. This will give manufacturers the ability to tune their system to changing environments. These OTP ROMs would be 
available in cheaper but more rugged plastic packages or in the form of IC chips [2].

As the automotive market becomes more lucrative, the list of key players in this arena becoming longer. The big names including Texas Instruments, Motorola, National, General Electric, Tesla, SGS-Thompson, Hitachi, Toshiba, Siemens and Harris. These vendors not only complete the innovations in device design but also in inventing new process suited for automotive electronics. The current processes used are Bi-polar, CMOS and DMOS (Dual-Gate MOS). SGS-Thomson is on an innovative experiment, combined structures of all three technologies in what they termed the BCD process. However, as custom linear devices [1] become more popular, the unanimous choice for process technology seems to be Bi CMOS.

\section{IN-VEHICLE ELECTONICS TECHNOLOGY}

Recently, a number of Japanese manufacturers have entered the field of heavy vehicle and passenger cars in the country, which may significantly change the future of the Indian automobile industry.

TABLE I. ELECTRONICS IN AUTOMOBILES

\begin{tabular}{|c|c|}
\hline \multicolumn{2}{|r|}{ Electronics in Automobiles } \\
\hline Entertainment & $\begin{array}{l}\text { - Digitally tuned radios } \\
\text { - Search/Seek/Scan station memory } \\
\text { - AM \& FM Stereo graphic equalizer } \\
\text { - Power Amplifier } \\
\text { - Noise Reduction } \\
\text { - System optical disk } \\
\text { - CD player radios } \\
\text { - Digital audio tape }\end{array}$ \\
\hline $\begin{array}{c}\text { Safety and } \\
\text { Convenience }\end{array}$ & $\begin{array}{l}\text { - Climate control } \\
\text { - Illuminated entry light } \\
\text { - Memory seats } \\
\text { - Heated wind shield } \\
\text { - Sensory wipers } \\
\text { - Auto door lock } \\
\text { - Automatic headlight dipping } \\
\text { - Voice controlled trunk } \\
\text { - Traction control } \\
\text { - Anti-skid braking } \\
\text { - Window control } \\
\text { - Air mag restraints }\end{array}$ \\
\hline Body Control & $\begin{array}{l}\text { - Multiplexed wiring } \\
\text { - Module-to-module communication } \\
\text { - Electronic suspension } \\
\text { - Cruise control } \\
\text { - Intermittent wipers } \\
\text { - Load sensitive braking } \\
\text { - Ride control } \\
\text { - Anti-theft alarm system } \\
\text { - Electronic steering } \\
\text { - Electronic muffler }\end{array}$ \\
\hline & $\begin{array}{l}\text { - Ignition spark fuel timing control } \\
\text { - Emission system } \\
\text { - Voltage regulator }\end{array}$ \\
\hline
\end{tabular}

\begin{tabular}{|c|l|}
\hline Power Train & - Alternator engine control \\
& - Transmission control \\
& - Idle speed control diagnostics \\
\hline & - Digital gauges \\
& - Engine diagnostic result \\
& - Service reminders \\
- Digital clock \\
Driver & - Trip navigation \\
& - Computer multitoned alarms \\
& - Heads-up display \\
& - Audio annunciator \\
& - CRT/LCD/LED display \\
& - Shiftes to empty indicator \\
\hline
\end{tabular}

The Japanese have introduced a number of electronic controls like electronic fuel management and automatic transmission to obtain more power from the same displacement engines with considerable fuel economy [3]. Electronic systems which can monitor, diagnose, display and control almost an endless variety of vehicle parameters are available. In-vehicle electronics technology caters for the needs of improved safety, better fuel efficiency [3], better engine control [4], transmission control [3], emission control, human comfort, navigation systems and various on board facilities. The various applications of electronics automobiles are given in Table [1].

\section{A. Engine Control}

The main component of an on-board computer system is the engine control module (ECM) or engine control unit [5][6]. These devices are interfaced with a vehicle's electronic system using a conventional wiring harness fitted with a multi-pin adaptor. The vehicle which has ECM/ECU controls the engine with the help of information received from sensors like coolant, temperature, crankshaft RPM, exhaust oxygen content, throttle position and in-take pressure. Based on the information received, it controls fuel injection ignition timing, idling speed, shift point and clutch lock up etc. Figure 1 shows an ECM used by Toyota in its cars called Toyota computer control system (TCCS). This system has a custom-made CMOS 8-bit microprocessor with up to $18 \mathrm{~KB}$ ROM [2][5]. The TCCS also uses a variety of sensors and actuators. For example, it has a Karman Vortex meter which detects air in-take. Toyota hopes to improve on TCCS by employing new technologies such as fuzzy logic and neural network for adaptive control. Bosch of Germany also designs integrated engine control systems. In fact, it introduced the first computerised engine control system in 1970 called "The Motronics" which combines ignition and injection in one unit. They have recently developed "Motronic M III" which uses a 16-bit processor. The system features sequential fuel injection and has both self-diagnostic and self-learning capabilities. BMW is expected to use M III $\mathrm{n}$ its hybrid models [6].

\section{B. Ignition System}

In earlier days the main part of ignition system was mechanically controlled chokes. Mechanically controlled chokes ae operated by a pull rod on the dash. The pull rod is 
linked to choke valve. When it is pulled out, the choke valve is closed. The driver must remember to push the control rod into the dechoked position as soon as the engine begins to warm up. If he does not, the carburettor will continue to supply a very rich mixture to the engine. This excessive richness will cause poor engine performance, high level of exhaust emissions, fouled spark plugs and poor fuel economy, as well as many problems. To prevent such problems, then invented automatic chokes with thermostatic spring [7][8]. It also had drawbacks. Then came electric automatic chokes. This type of choke includes an electric heating element. The purpose of this heater is tom assure faster choke opening. Emission and choke opening time became $11 / 2$ minutes [8]. With the choke valve closed, the engine is being fed a very rich air-fuel mixture. The exhaust gas is thus loaded with unburned $\mathrm{HC}$ and with $\mathrm{CO}$. Emission of unburnt $\mathrm{HC}$ and $\mathrm{CO}$ are relatively high during the early stages of engine warm-up [7][8]. The electricassist choke reduces the length of time during which these pollutants are fed into atmosphere. On electronic point of view 11/2 minutes is a large duration [8]. To reduce this time delay electronic ignition system was introduced.

\section{Electronic Ignition System:}

Mechanical and vacuum spark ignition systems are fast becoming obsolete. Modern car manufacturers use pulse generator systems, for triggering ignition. Based on inputs from various sensors, the computers are capable of determining optimum ignition point under different conditions of engine operation. The advantages of such electronic ignition systems are improved engine starting, better idle speed control and reduction of overall fuel consumption.

\section{Electronic Fuel Management (EFM):}

The basic function of EFM is shown in figure 1. It is to provide the engine cylinders with precise quantities of fuel in the correct proportion as well as air to achieve the desired engine performance, good fuel economy, proper emission levels and comfortable driving. The fuel is controlled by electrically actuated solenoid injection valves [9].

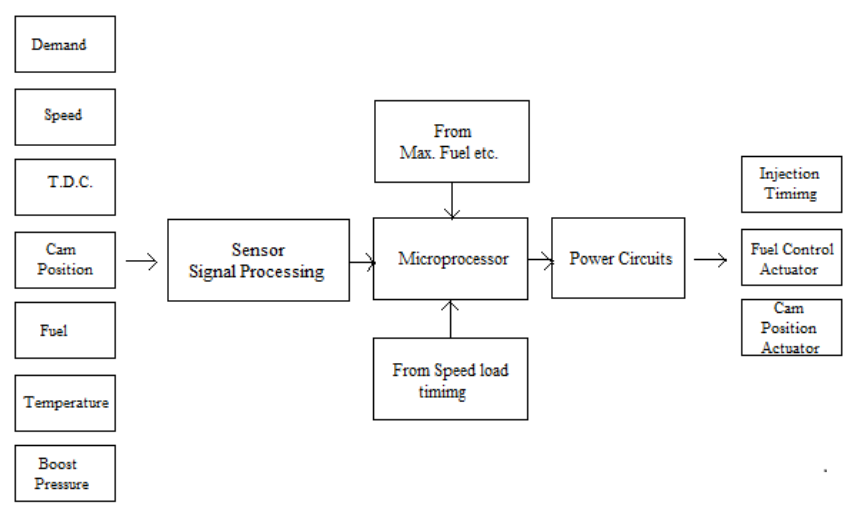

Figure 1: Electronic Engine Management

A fuel injection system that is controlled by electronic means. This system was designed for Volkswagen flat-four, air cooled engine. But the basic ideas apply to all electronically controlled fuel-injection systems. The fuel is injected into the intake manifold's behind the intake valves. The injection is timed to coincide with the valve opening by triggering contacts in the injection distributor. The amount of fuel injected is controlled by the length of time the fuel injectors are open. This in turn, is determined by sensors which sends electrical signals to transistorised control unit. The injection phasing and duration is controlled by the electronic control unit (ECU) which computes the needed quantity of fuel from measurements of inlet manifold pressure, engine speed and air temperature combined with a knowledge of the engine's physical and operating parameters. Both the distributer type of fuel pumps has undergone modifications to produce standard FIPs for ranging from $1 \mathrm{KW}$ output per cylinder to $250 \mathrm{KW}$ output per cylinder [9]. Some of the new FIPs have integrated sensors and actuators with an internal microprocessor circuit. The development of integrated injection logic to integrate both analog and digital functions in a single chip, smart sensors to interface directly with the microprocessors and the fast response actuators to bridge the gap between the logic and power to be controlled, have greatly simplified the controls on the vehicles.

\section{Advance in Electronics:}

The advent of single-chip microprocessor has contributed significantly to the development of integrated electronic controls. A single microprocessor can now be used for electronic fuel management including electronic governing, automatic transmission and digital displays of engine and transmission parameters to the driver and for vehicle diagnostics. The development of smart sensors like semi-conductor strain gauge sensor, magnetic torque sensors, lean air fuel ratio sensors, mass air flow sensors and cylinder pressure sensor have significantly changed the situation. In these smart sensors, the essential device is a semi-conductor which has built-in signal processing circuits and custom built ICs, that can directly interface with the microprocessor.

\section{Engine Sensitivity Functions:}

For an engine control system, its output can be described by the vector equation

$$
\mathrm{Y}=\mathrm{Y}(\mathrm{u}(\mathrm{t}), \mathrm{a})
$$

Where $\mathrm{Y}$ is the engine output vector (speed, torque, emissions) $-\mathrm{u}(\mathrm{t})$ is the input from the driver (throttle command) and $\mathrm{a}$ is the parameter of interests in equation (1). The use of engine sensitivity functions to investigate the sensitivity of engine control systems to changes in the values of parameters of the engine or control system should enable the matching of sensors, signal processing circuits and actuators more accurately. All the functions of the engine parameters including the cooling and combustion parameters are being optimised. The entire control system on the engine is termed as "Electronic Fuel Management". The trend is to obtain more power from the same displacement engines as per the load demand with the help of electronic fuel management and automatic transmissions. 


\section{Automatic Transmission Control}

The drive assembly contains a small pinion that in operation, meshes with teeth cut in the flywheel. Tis provides gear reduction, so that the armature must rotate about fifteen times to cause the flywheel to rotate once. The armature may revolve about 2000 to $3000 \mathrm{rpm}$ (revolution per minute) when the starting motor is operated. This causes the flywheel to spin at starting motor is operated. This causes the flywheel to spin at starting motor is operated. This causes the flywheel to spin at speeds as high as 300 $\mathrm{rpm}$. This is ample for starting the engine. After the engine starts, it may increase in speed to $3000 \mathrm{rpm}$ or more. If the starting motor drive pinion reminded in mesh with the flywheel, it would be spun at $45000 \mathrm{rpm}$ because of the 15:1 gear ratio [10]. This means that the armature would be spun at this terrific speed. Centrifugal forces would cause the conductors and commutator segments to be thrown out of the armature, ruining it. To prevent such damage automatic meshing and de-meshing devices are used. In automatic transmissions, the varying ratios between the engine crankshaft and the wheels are achieved automatically [10]. Automatic transmission does the job of shifting gears without assistance from the driver. This is, the driver does not need to shift the gears. They start out in low, as the car begins to move forward, they shift from low gear into intermediate and then high as the car pick up speed. The automatic transmission automatically selects the ratio required by engine speed and operating conditions. Automatic transmissions use a torque converter as well as hydraulic controls [10].

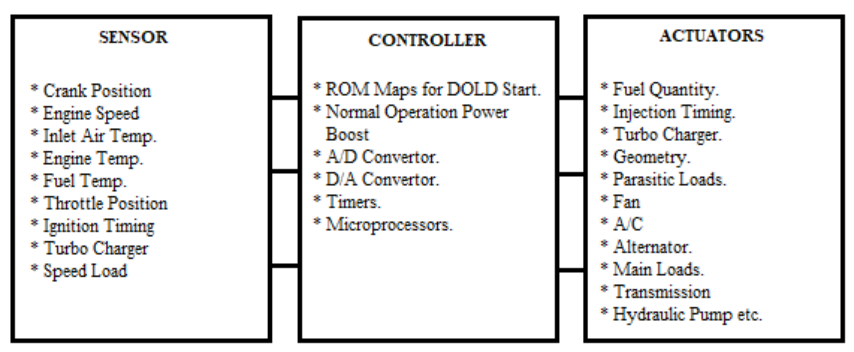

Figure 2: Block diagram of electronic transmission control

Electronic controls help in optimisation in transient operation of the engine and the controls of the driven equipment are linked. On the cars with automatic transmission, a special switch prevents starting while the car is in gear. The switch (neutral safety switch) is connected between the ignition switch and the solenoid. This switch is open at all transmission-lever positions except 'Neutral'. Late-model cars have a clutch safety that prevents starting if the clutch is engaged. That is, the clutch pedal must be depressed at the same time that the ignition switch is turned to 'Start'. The movement of the clutch pedal closes the safety switch so that the circuit to the starting motor can be completed. The purpose of the switch is to prevent starting with the transmission in gear and the clutch engaged. If this happened the engine might start and the car might move before the driver was ready for it. And that could lead to accidents.
Electronic Transmission Control: The use of electronics to control the automatic shift sequence of the transmission allows reduction in transmission, power losses, closer matching of transmission gear ratio and reduction in over all fuel consumption. Electronic transmission control also uses single chip microcontrollers to allow better performance of the vehicle power train. One of the best experiments in electronically control variable transmission (ECVT) is from Brog-Warmer. This ECVT has three sub system: Start clutch control, ratio control and line pressure control. Each uses a microprocessor that generates P.W.M. duty cycle signal which operates an electro hydraulic solenoid valve. The EVC then processes the optimum throtte nd shift level position, oil pressure and shaft speed. Mercedes Benz also offers an ECVT system in its $300 \mathrm{E}$ model called 4-matic. This is made from a model made by Bosch. Toyota also provides ECVT system in its cars since 1981 and so do other japanese manufacturers. The use of an automatic electronic control, having an IC up/down counter with a suitable decoder; enables the selection of the four forward and two reverse gears in a logical sequence. For any type of heavy vehicle, maximum effort is needed onlyin the first and second gears to overcome vehicle inertia and (with automatic selection of thrird gear onwards) as a funtion of speed; the present five or six ratio design of gear boxes can be increased to a greater number of ratios, thus yielding lower fuel consumption as well as improving gear shift quality. Since diesel engines typically tend to be most fuel efficient witin a narrow speed range, increasing the number of speed ratios in a transmission will more closely match the actual torque curve to the ideal torque curve. The performance characteristics of Merceds Benz E 250 is simulated as shown in figure 3 [11] [12].

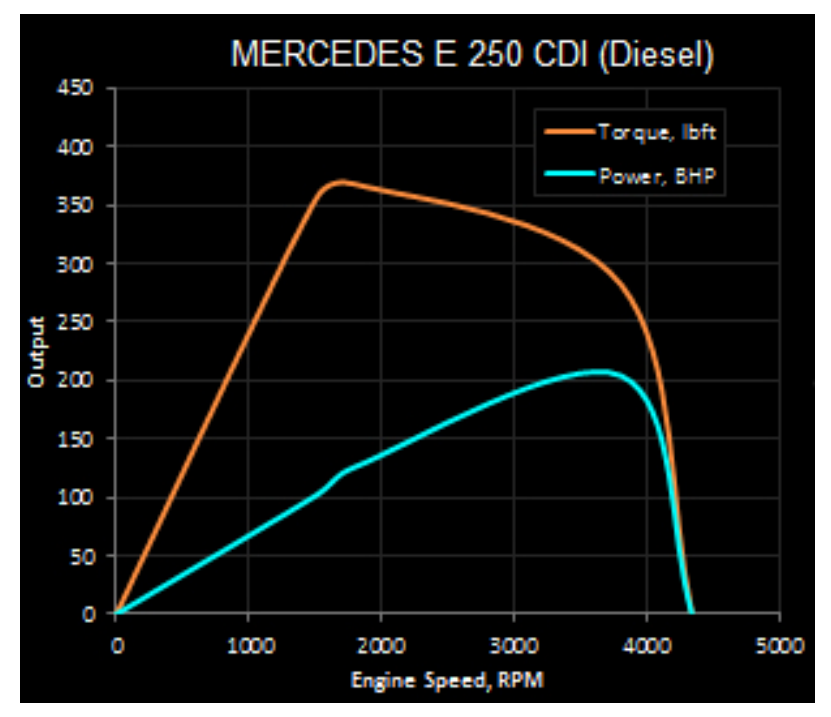

Figure 3. Diesel engine Torque/Power speed characteristics

Automatic electronic transmission control will enable the engine to be operated in a narrow speed range with the mentioned benefits. The nature of transmission control depends primarily on the nature of transmission itself. The one shown in figure 4 is for gear boxes using epicycles gear 
trains and a torque converter, the electronic control being much simpler in design than for, say, a constant mesh counter-shaft gearbox. Basically, the gear/transmission controller has to send approximate signals to control the on/off states of electro-hydraulic solenoid directional control valves within the transmission [11] [12]. These in turn control the transmission behaviour and operation with respect to directional changes (forward/reverse) gear selection, gear shift and torque converter operation (with suitable delays in between gear changes and torque converter operation). The control system flow diagram is given in figure 5 [11].

The basic circuits are logic circuits, switching and driving circuits. The logic circuit depends on the number of input parameters such as the vehicle speed, engine load (throttle or fuel rack positions) and the kick down facility. The switching circuits are an IC up/down counter with suitable decoder. In the driving circuits the normal power transistors are used to drive the electrohydraulic solenoid valves. Two micro switches are used to effect up changes and down changes of gear manually. There are two time delays-one between each gear change and the other for torque converter operation.

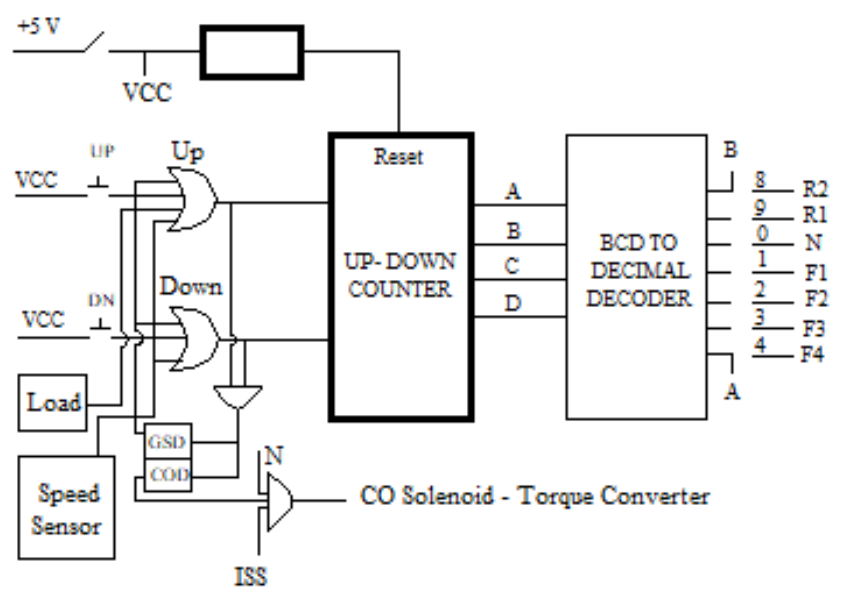

Figure 4: Automatic transmission controller for epicycle gear box using an UP/Down IC counter

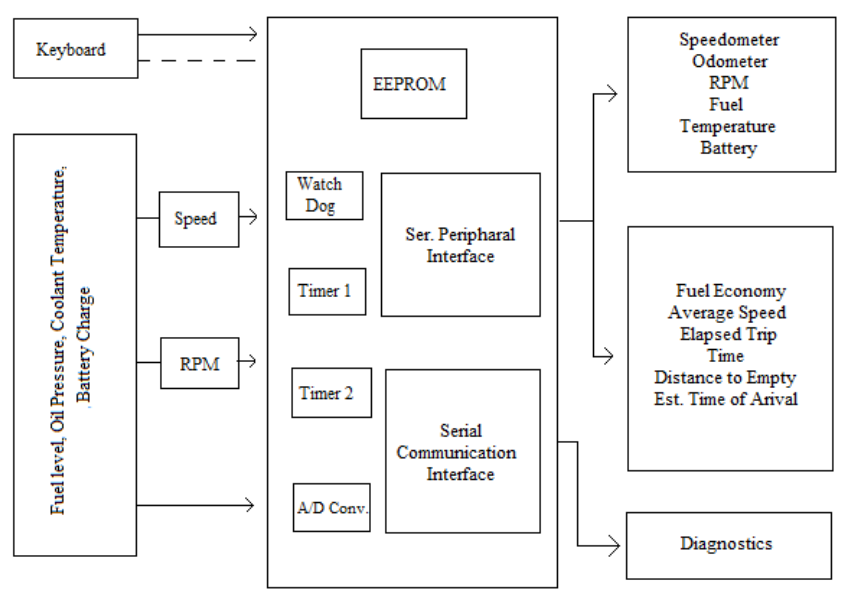

Figure 5: Drive Information System

\section{Braking System}

In earlier days' disk-brake systems were used. Diskbrake systems are used. Disk-brake systems have a metering valve. This valve keeps the front brakes applying until the rear brakes apply. If the front brakes were applied first, the car could be thrown into a rear-end skid. Many brake shoes have tell-tale tabs [13]. The purpose of these tabs is to warn the driver that the brake linings are worn down and that new linings are required. When the brake linings are worn down, the tabs touch the disk when the brakes are applied. This gives off a scrapping noise that warns the driver to get brake service. The dual or split braking system uses a pressure differential valve to operate a warning light. The purpose of this light is to warn the driver if one or the other half of the braking system has failed. The valve has a piston that is centred when both front and rear brakes are operating normally. However, if one section fails then there is low pressure on one side of the piston. The high pressure from the normally operating side pushes the piston to one side. This movement pushes up the plunger of the brake warning light switch. Contracts inside the switch close [13]. This connects a warning light on the instrument panel to the battery. The light then comes on to warn the driver that there is trouble in the braking system.

\section{Anti-Lock Braking System (A.B.S.)}

2. A lot of accidents occur as a result of wheels jamming due to sudden braking. An anti-lock braking system (A.B.S.) improves the stopping performance of a vehicle by pulsing the brake at each wheel to prevent it from locking as the driver applies the brake. The A.B.S. microcontroller chip measures the speed of each braked wheel to determine if one of the wheels is locked. If it is so, then the brake pressure to that particular wheel is lowered until it unlocks A.B.S. has to be ultrareliable and for this reason most systems use some form of redundancy or built-in checking element [14]. The three major elements in an A.B.S. are wheel speed sensor, microcontrollers and brake pressure modulators. Intel is the main supplier of microcontrollers to major A.B.S. manufacturers such as Bosch, Teves, Celsey-Hayes and Bendix [14]. Currently, 8-bit microcontrollers are being used for low-end systems. For high-end application, however 16-bit controllers are needed. Some manufacturers are trying to combine A.B.S., traction control and cruise control in one module. For such applications a 32-bit microcontroller is perceived. Toyota claims to have equipped all its models with an A.B.S. system. G. M. has chosen 'Delco Moraine' as its supplier of A.B.S. and will make this system standard in all its cars by 2020 . 
3. Combi-Braking - Brakes are intended to stop a moving vehicle to halt. Depending on the type of vehicle different types of brakes are used in vehicles like drum brakes, disk brakes etc. As we know for applying the brake, brake lever is applied in two wheelers whereas brake pedal is applied in other vehicles like cars, trucks etc. In heavy vehicles or four wheelers the functioning of brake is through hydraulic system. It applies to all the wheels equally and simultaneously. This is not the case in two wheelers. In two wheelers when the brake lever is applied it will either apply in the front or rear wheel which may cause skidding of the vehicle. To avoid this both front and rear brakes are to be applied sensibly [15]. Every rider may not possess this sensibility. Hence the combibrakes. In combi-braking system (designed for scooters and bikes) brakes will act on front and rear wheel together when it is applied. This braking system helps in achieving better operational efficiency while braking a vehicle and thus avoids skidding. An equalizer is attached to the system. Pressing the left lever activates the equalizer which distributes the braking force between front rear wheels giving a perfect balance to the driver.

\section{E. Traction Control}

Traction control helps the driver get a car moving smoothly, by allowing it to advance even on slippery or gravelly surfaces, by reducing engine torque and suppling the brakes to one or both drive wheels when they are slipping-even if the driver keeps a heavy foot on the accelerator. Traction control is considered to be the opposite of A.B.S. because it provides slip control on acceleration. This system is known to be the fastest developing component of chassis electronics as it shares many components with A.B.S [13] [14]. Traction control replaces various limited slip differential system in use today with an electronic control until that responds to sensor measurements of slippage at varying engine speed. Honda claims to be the first company to produce a front wheel drive traction control system. The system controls the engine by managing fuel-flow levels and ignition timing. An ECU monitors and processes data from wheel speed sensors and steering wheel angle sensors. The ECU then provides fuel injection and ignition timing. Other manufacturers such as General Motors and BMW are providing the combination of A.B.S. and TCS made by Bosch as standard equipment in their high-end cars. Texas Instruments have developed a configurable high-performance controller which would help manufacturers reduce cost of combined A.B.S. and TCS module to one-tenth [13] [14] [15].

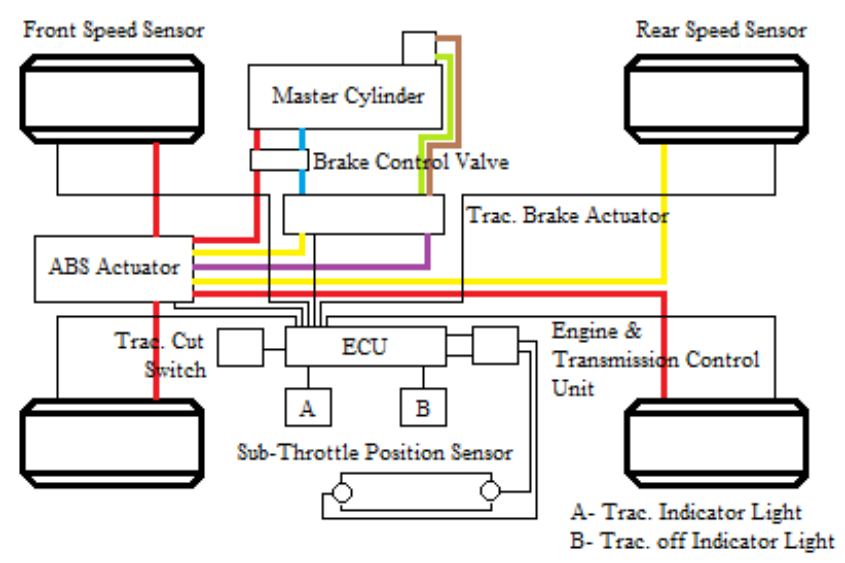

Figure 6: Traction Control System \& Speed Sensors

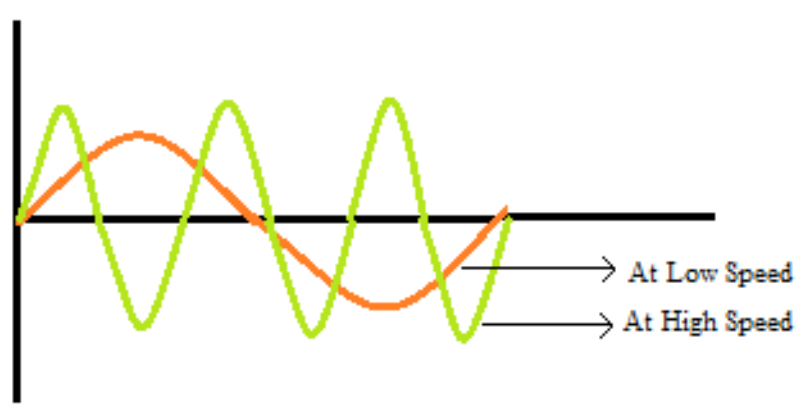

Figure 7: Generated wave form of traction control

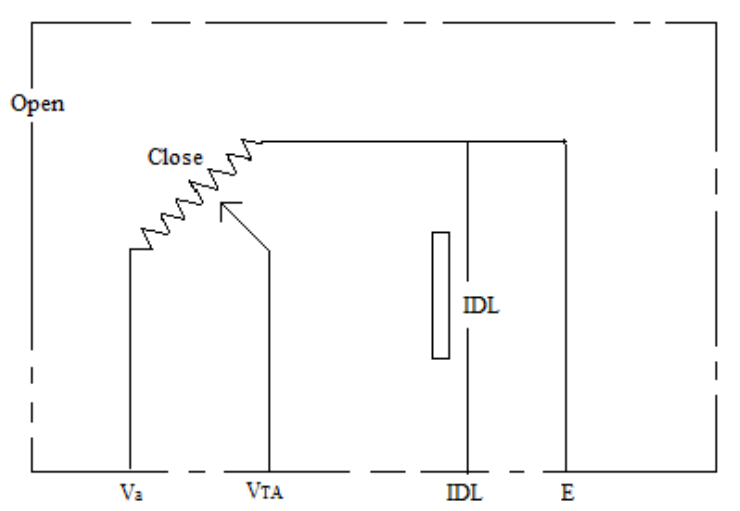

Figure 8: Sub throttle sensor

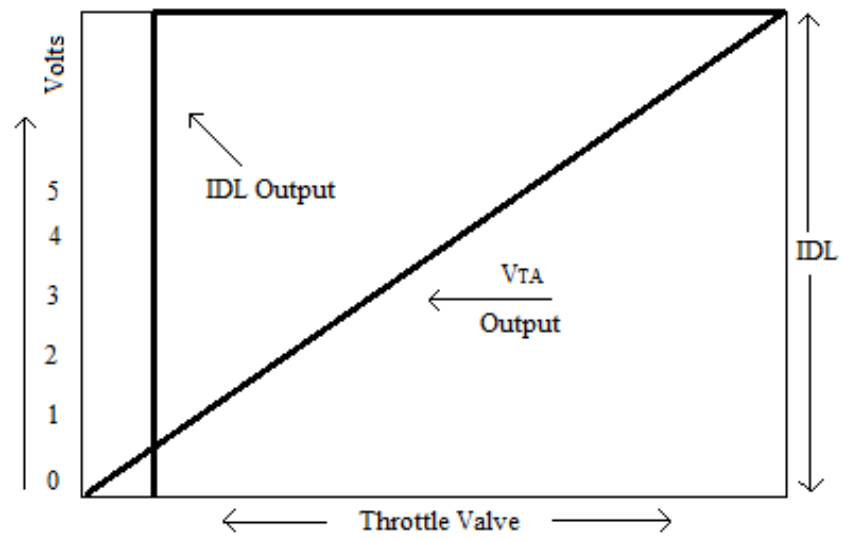

Figure 9: Sub throttle sensor output 


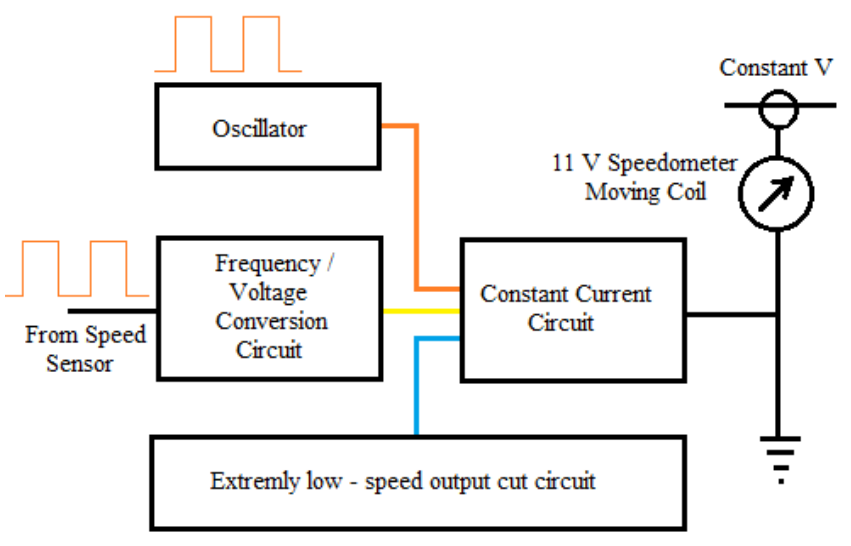

Figure 10: Speedometer Drive Circuit

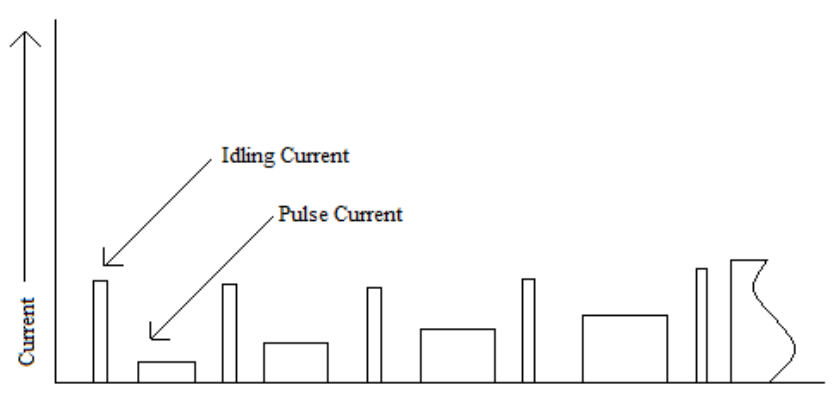

Figure 11: Speedometer drive output

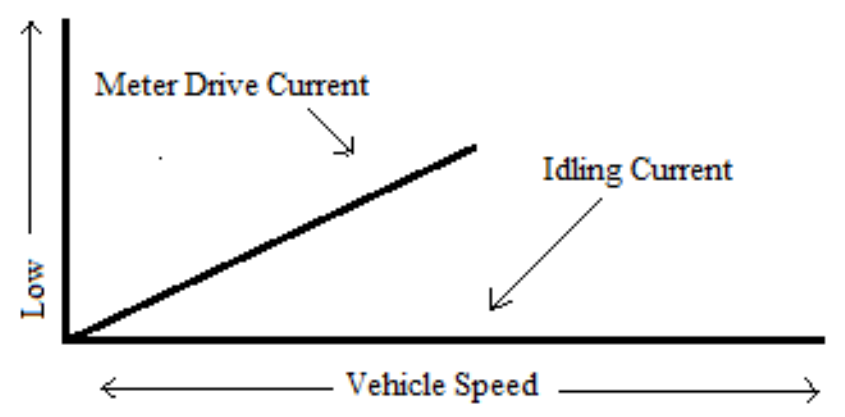

Figure 12: Speedometer drive current

\section{F. Steering Assistance}

Another area of electronics application is the steering, where activity ranges from augmenting or replacing hydraulic power assistance to active rear-axle kinematics. In an experiment by Toyota, the conventional hydraulic power steering has been replaced with an electronic motor. By electronically controlling the motor they have been able to produce a system to provide power supports depending on vehicle speed. Bosch is also working on a similar system [16]. In their design, an electric motor transfers its force directly to the steering column via. Reduction gear and dispenses with hydraulics altogether. The motor is activated by an electronic controller that receives data through torque sensors fitted to the steering column. A steering assistance system can also be put on the rear axle steering system. At the international motor show in Frankfurt in 1989, Siemens showed for the first time an electronic controller for active rear axle kinematics [16]. From the steering angle of the front wheels and the vehicle speed, a microcomputer system computes the optimum rear axle steering angle in terms of vehicle motion dynamics.

\section{G. Active Suspension}

The automatic-level-control system takes care of changes in the load at the rear of the car. In a car without level control, the springs will give and the car will settle when a load is added to the rear seat or trunk. This causes the headlights to point upward. The automatic control prevents all this by automatically raising the rear end of the car to level when a load is added. The level control also automatically lowers the rear end of the car to level when load is removed [17]. The automatic-level-control system includes a compressor, a height-control valve and two special shock absorbers. The height control valve has a time delay mechanism that allows the valve to operate only after several seconds. This mechanism prevents fast valve action, which could operate the system after each bump or hole in the road. In other words, the automatic-level-control system works only when loads are added or removed from the rear of the car. For optimum ride characteristics and passenger comfort many manufacturers have started providing an automatic levelling control system or an active suspension. In such a system, a height sensor is mounted on the vehicle. Attached to this sensor is an actuating arm which is linked to the rear suspension. As the vehicle load changes the displacement of the automobile body to the suspension, the system triggers the actuating link connected to the side height levelling control valve. Toyota has such a system called 'piezo-tems' (Toyota Electronic Modulated Suspension), in it a piezo-sensor monitors the road surface conditions [17]. A piezo-actuator then uses the inverse piezo-electric effect to change the damping force of the shock absorbers to match driving and road conditions. BMW also has a similar system called electronic damper control.

\section{H. Electronic Climate Control}

Many high-end cars are equipped with systems that automatically control the heating, ventilation and airconditioning systems. Such systems are controlled through ECM, which receive input signals from either switches on the instrument panel or the sensors [18].

\section{Controls:}

In a fully automatic system, the driver simply sets the temperature as desired. The system takes over from there. The system will cool when cooling is needed to maintain the temperature set. The system will also heat when heating is needed to maintain the pre-set temperature. 


\section{Automatic Temperature Control:}

The control panel has two levers. The upper lever can be moved to select the desired temperature. The lower lever can be moved in all the way to the left to get automatic action in high. That is, the blower will operate at the maximum speed until the desired temperature is reached. Then the blower will slow down and operate just fast enough to maintain the desired temperature. If slower action is desired, the driver can set the lever at low. If the driver only wants untreated outside air to enter the lever is set at VENT [18]. At this setting the outside-recirculating door is moved down so that outside air enters. To defog or defrost the windshield, the driver sets the lever at either of these positions. In this system there is a delay circuit in the heating section [18]. This delay circuit prevents the blower from coming on until the water circulating in the heater core is warm. This prevents the circulation of cold air, which would be uncomfortable for the people in the car.

\section{On-Board Information and Guidance System}

Many luxury automobiles have an on-board computer system with CRT terminal that allows the driver to quickly access different kinds of information such as fuel consumption (average and current), average vehicle speed, outside air temperature, miles to empty on existing fuel supply, estimated time of arrival at destination, stored maps, time and data reminder. Such a system facilitates better transportation management. Thus, we see that electronics has pervaded almost every aspect of automobile subsystems and is playing a major role in achieving fuel economy, reducing noise, reducing exhaust pollution, providing better passenger safety and comfort. GPS assisted navigation systems are getting common which assist in on road direction for transit. This feature is enhanced now-adays with help of artificial intelligence (A.I.) which helps in reroute to destination by avoiding heavy traffic.

\section{J. Automotive Saftey and Comforting Devices:}

Auto motives enhance user experience by the additional features which provide the user with comfort and safety. This features depends on the class of the automobile from hatchbacks to luxury sedans.

\section{Circuit Breakers and Fusible Link:}

Circuit breakers protect the electrical circuits in the car from over loads. Circuit breakers are used in some circuits, such as the head light circuit. The circuit breaker has a small winding that carry the current in the circuit. When the current is too high, the winding magnets opens points to open the circuit. The advantage of the circuit breaker is that it keeps resetting itself. Thus it gives a warning of trouble but does not completely kill the circuit. For instance, if excessive current starts to flow in the headlight circuit, the circuit breaker will operate. The light will-come on and off, warning the driver of trouble [19]. The flashing light gives the driver enough time to pull over to the side of the road and stop.

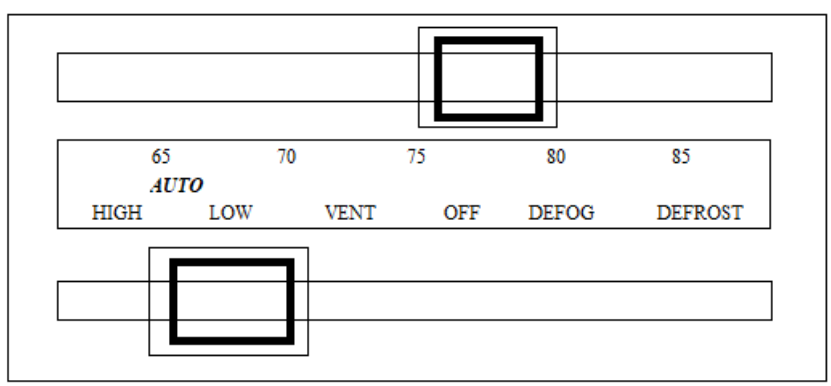

Figure 13: Instrument control panel for a fully automatic heater-air-conditioner system.

For added protection, many cars have fusible links in the insulated battery cable and in the larger high-currentcarrying wire. A fusible link installation is simply a wire several gauges smaller than the wire it is protecting. If a short or ground occurs, the fusible link will burn in two before the larger wire. As a result, the other part of the circuit will not be damaged [19]. The complete system includes headlights, parking lights, turn signals, side marker light, stop lights, backup lights, tail lights and interior lights. The interior lights include instrument panel lights, various warning and indicator lights and courtesy lights that turn on when a car door is opened.

\section{Phototube Headlight Control:}

This is an electronic device that automatically selects the proper headlight beam. It holds the lights on high beam until a car approaches from the other direction. The headlights of an approaching car trigger the phototube to switch automatically from high to low beam. When the other car has passed, the phototube automatically switches back to high beam. The device has several names: 'Automatic Eye', 'Guide Matic', 'Automatic Headlight Dimmer' and so on. The phototube unit is mounted either on the top left side of the instrument panel or behind the radiator grill. In either place the unit is in line with the lights of oncoming cars. The phototube is an electronic tube that releases electric current when light of specific intensity strikes it. The current is very small, but it is amplified by a special amplifier unit. This provides enough current to operate a power relay and shift the headlights from high to low beam. The driver can still use the manually operated dimmer switch to override the phototube.

\section{Indicating Devices:}

Innovation in indicating devices is the sensor panel, called the Electro Sensor Panel (E. S. P.) introduced by Toyota in 1974 [20]. This panel is installed on the roof of the car above the driver. It is connected to sensors in the light circuits, brakes, windshield washer, battery, cooling system, radiator and engine crank case. The sensor panel has eleven warning lights which come ON if something need attention. For example, if any of the four lights at the top of the panel light (license, brake, tail, head), it indicates trouble in that circuit. If one of the headlights gets burnt out, "HEAD" would come on to warn the driver of the trouble in 
that circuit. The four "Fluid Level" lights (W-Washer, battery, Radiator, Engine Oil) indicate low fluid level in any of these four areas. That is, if the engine oil drops to a low level, the "Engine Oil" light would come ON. The "Brake" section of the panel warns of low brake fluid, loss of vacuum in the power-brake unit or excessive brake lining wear [20]. In addition, some cars have a tachometer which indicates engine speed in revolutions per minute.

\section{Lights in Automotive:}

In addition to headlights and stop lights, cars have courtesy lights, turn signals and warning-blinker system. The courtesy lights are operated by switches in the doors. When a door is opened, the switch closes to connect the internal lights in the dome or side. The lights come on so a passenger or driver can see. Turn signals are operated by separate lever on the steering column. When the driver flips this liver for a turn, lights at the front and rear of the car flash on and off. Some cars are equipped with sequential turn-signal lights. That is, there are several separate bulbs that come on in sequence, starting near the rear centre of the car and moving to the side. In addition, many cars are equipped with side lights at the front of the car. This provides additional light to the driver so he can see what he is turning into. The turn signal lever is returned to neutral when the driver turns the steering wheel back to straight ahead. The warning-blinker system is operated by separate switch usually located on the steering column. When there is an emergency of some sort, the driver can actuate the system by closing this switch. Then all the outside car lights flash on and off every few seconds. This system is used when the car has stopped. It is no normally used when the car is operating on the highway.

\section{Back-Up Light and Camera:}

When the gearshift lever is moved to reverse, the linkage closes a switch that connects the back-up lights to the battery and the back-up camera to the dashboard. Thus they come on automatically. This is a warning that the car is about to be backed. The light also gives the driver a chance to see where the car is going. Some cars are attached with proximity sensors which assist the driver to assess the distance between the automobile and the object with help of buzzer for proximity assisted reverse control.

\section{Stoplight Switch:}

The stop light switch is used in almost every car now-a -days. When the brake pedal is pushed down for braking, it causes the switch contacts in the stop light switch to close. This action connects the stoplights to the battery so that the stoplights come on.

\section{Seat Adjuster:}

In earlier days' seats are of fixed type. Sitting for a long time in a straight manner is very difficult. For long journeys driver has to sit straight for a long time. This caused uncomfortableness and back pain. To avoid this electronic seat adjuster were invented. Electronic seat adjusters are motor powered. The seat can be adjusted forward or backward or up and down and tilts the seat backward or forward. This mechanism causes the seat to move in the direction selected by the driver.

\section{Seat Belts:}

The purpose of seat belts is to restrain the driver and passenger if there is an accident. During a front-end crash, for example, the car is brought to a sudden stop. But everything inside the car continues to move forward until it hits some solid object. An unrestrained passenger would continue to move forward until he/she hit the windshield or the instrument panel. This is so-called second collisions that hurt and kill people. However, if the passengers and driver are wearing seat belts, they will be restrained. The seat belts installed on earlier model cars were optional; That is, the driver and passengers did not have to use them. Then, on later-model cars, a warning buzzer was incorporated which buzzed if the seat belts were not fastened. The latest arrangement is called the seat belt-starter interlock system. This system requires the driver and any front seat passenger to buckle their seat belt before engine can be started. The purpose of these devices is to urge or require, the driver and front-seat passenger to use their seat belts and this protects themselves from injury or death in case the car is involved in an accident.

\section{Front-Seat-Belt Warning System:}

This system includes a buzzer and a red warning light which remind the driver and passengers to buckle their seat belts. The reminder signals (light and buzzer) come on if the seat belts are not buckled and the driver starts the engine. The outboard seat-belt retractors have switches which are closed when the seat belts are retracted. When the seat-belts are pulled out and buckled, the retractor switches open thus preventing the buzzer and light from coming on. There is a sensing switch under the passenger side of the front seat. This switch is interconnected with the right hand seat-beltretractor switch. The sensing switch closes when a weight of more than a few kilogram is placed on the seat. Then, if the passenger fails to buckle up, the retractor switch, also closes and completes the circuit to the buzzer and light. Now, when the driver releases the parking brake or shifts into gear, the reminders come on.

\section{Seat-Belt Starter Interlock System:}

This system makes it necessary to buckle the front seat belts before the engine can be started. The sequence required of the driver is: Get in the car-Buckle the seatbelts of driver and passenger - Insert the ignition key and turn the switch to start [21] [22]. This is the only sequence that will get the engine started. If the seat belts are not buckled or are buckled before the occupants are seated, a relay operates to activate the warning light and buzzer. Also, the light and buzzer will come on if any front-seat occupant unbuckles after the transmission has been shifted to a forward drive position [21].

\section{Open-Door Warning Buzzer System:}

This system operates a buzzer if any of the door is open with ignition key in the ignition switch. When the ignition key is left in the ignition switch, a warning switch is closed. 
The warning switch is in the ignition switch and is connected to the door switch. Then, if the door is opened the door switch is closed, this completes the circuit to the horn relay. This relay now buzzes. The system warns the driver that the ignition key is still in the ignition switch and should be removed. An ignition key in the ignition switch of an unoccupied car is an invitation to thieves.

\section{Headlights ON Warning Buzzer:}

This system is usually combined with the open-door warning buzzer system. When the headlights are on and the driver's door is open, a warning buzzer sounds. The system warns the driver to turn off the headlights before leaving the car.

\section{Security Alarm System:}

This system, sounds an alarm if a thief tries to force entry to any door, the hood, the trunk or the tailgate. The alarm consists of the horn sounding at about 90 cycles per minute for 3 to 5 minutes. In addition, the headlights, taillights and side marker lights flash on and off at the same time. When either front door is locked with the key, the system is armed. That is, it is ready to sound the alarm if any attempt is made to force entry into the car. The system can be turned off by using the door key to unlock the door.

\section{Collapsible Steering Column:}

The collapsible steering column is a safety device. It will collapse on impact. For example, in a front-end crash, the driver will be thrown forward and into the steering wheel. The impact will cause the steering column to collapse and thereby cushion the driver's impact.

\section{Airbags:}

Airbags are a passive safety feature that protects the driver and passenger in a car accident." Passive" means that the driver and passengers do not have to do anything to be protected by the airbags. This is in contrast to the seat belts, described above that require an action-buckling up. Many people do not bother to buckle up because it is "too much trouble". As a result, there are far more highway injuries and deaths than there need be. The principle of airbag system is simple. At the instant that a crash occurs, the airbags are blown up, they give the driver and passenger a cushion into which to move. The airbags absorb the forward motion of the occupants and save them from hitting anything hard that could injure them [25]. At impact, the passenger is sitting back in the seat in a normal position. At $1 / 30^{\text {th }}$ second after the crash starts, the airbag system gets actuated [23][25]. The bag is already pushing out from its position in the instrument panel. The system is actuated by bumper detector. This detector contains a switch that is closed when the car is suddenly decelerated that is, when it is brought to a quick stop in an accident. When the switch closes, the airvessel and inflator assembly is actuated. The air-vessel is filled with compressed gas. When it is actuated this gas is released and it flows into the airbag. The action is almost instantaneous. After 2/30 second after impact, the airbag is almost fully inflated and the passenger has moved forward into the airbag [23]. Now, a fraction of a second later when the force of the passenger's forward motion has been completely absorbed, the airbag begins to deflate [23] [25]. The air bag has relief holes for this purpose. The quick deflation, after the airbag has done its job, permits the passenger to get out of the car.

\section{K. Power Steering}

Power steering assists the driver to steer the auto-mobile by augmenting steering effort needed to turn the steering wheel, hence it lets the automobile turn effortlessly in a turn. This is accomplished by using hydraulic or electric acctuators. Turning of automotive wheels need more effort at lower speeds. Power steering changes this effort required to turn the automotive at lower speeds with the help of hydraulic or electronic acctuators. Feedback system is the backbone of power steering system. In hydraulic actuator, it consists of a hydraulic cylinder which is part of a servo system; which is mechanically connected between the steering wheel and the linkage that steers the wheels. This feature lets the driver steer the automotive even if the actuator fails [27]. In electric actuators it uses an electric motor to provide the assistance to the system instead of the hydraulic limbs.

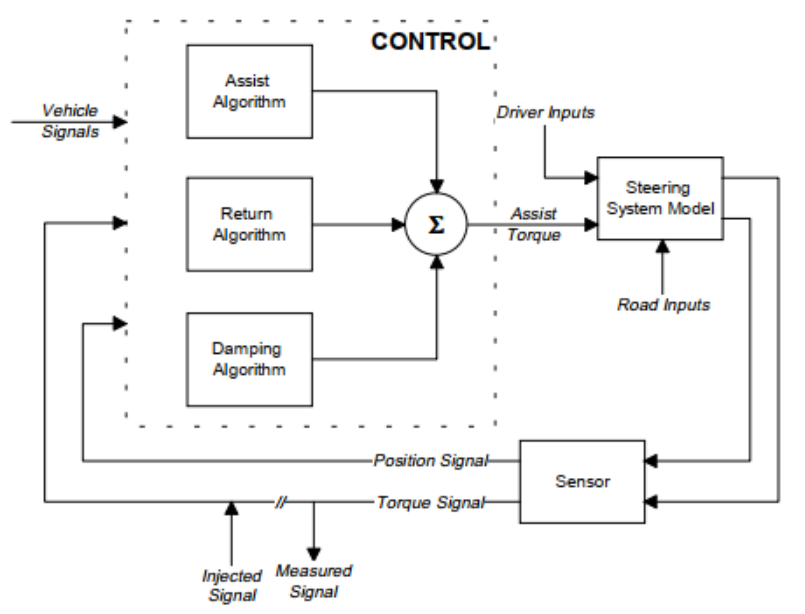

Figure 14: Block diagram of power steering system

\section{Waymo - Google AI Car}

In December 2016 Google launched Waymo LLC. It is a self-driving technology on automotive industry. Waymo is a driverless car with no steering wheel, brake pedal and gas pedal making it world's first completely self-sufficient car. Waymo was launched in midst of huge concern of lawmakers across the globe. The concerns were over the reliability of the system, regulation of emergency system, and operation of the autonomous car. Waymo uses two forward radars, one reverse radar, eight cameras, several lasers and twelve ultra-sonic sensors [28]. These sensors give 360 degree views to the AI powered control system of the Waymo. These sensors detect objects in a span of 300 meter. Short range lasers detect and focus on objects near the automotive. Google has officially recorded 12 collisions of which eight of them were rear end collisions by drivers of 


\section{International Journal of Engineering Applied Sciences and Technology, 2019 \\ Vol. 4, Issue 6, ISSN No. 2455-2143, Pages 163-176 \\ Published Online October 2019 in IJEAST (http://www.ijeast.com)}

other automobiles at signals and traffic lights [28]. Waymo is improving is improving its customer driver experience by reducing rapid start-stop and tailgating of vehicles in the neighbouring lanes and vehicle in front of the AI powered car.

\section{CAse STudy : Toyota Computer-Controlled SYSTEM (TCCS)}

TCCS (Toyota Computer-Controlled System) is the general name for a system which exercises comprehensive and highly precise control of the engine, drive train, brake system, and other systems by means of an ECU* (electronic control unit), at the heart of which is a microcomputer. Previously, TCCS was used as an engine control system for only EFI (electronic fuel injection), ESA (electronic spark advance), ISC (idle speed control), diagnosis, etc. Later, control systems utilizing other separate ECUs were developed and adopted for the control of systems other than the engine also. The ECU used for conventional EFI in export models beginning in 1979 was the analog circuit type, which controlled the injection volume based on the time required for a capacitor to be charged and discharged. The microcomputer-controlled type was added beginning in 1981. That was the beginning of the engine control system using TCCS. Now, however, the TCCS engine control system not only controls EFI, but also ESA, which controls ignition timing; ISC, which controls the idle speed, and other such advanced systems; as well as the diagnostic, fail-safe, and back-up functions [24].

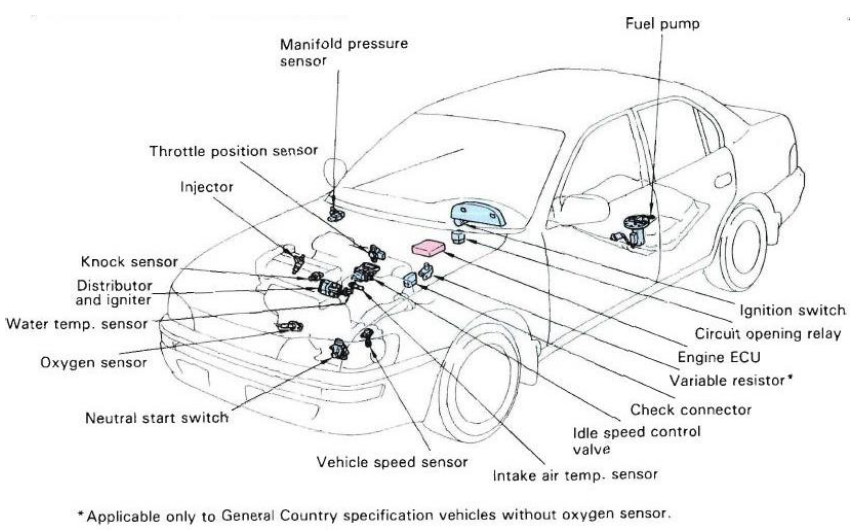

Figure 15: TCCS unit with control modules

The functions of engine control system include EFI, ESA and ISC which control basic engine performance [24]; a diagnostic function, which is useful when repairs are made; and fail-safe back-up functions, which operate any of these control system malfunction. In addition, there are auxiliary engine control devices on the engine, such as the OD cut-off control system and others. These functions are controlled by the engine ECU.

Functions of TCCS:

\section{Electronic Fuel Injection (EFI)}

An electric fuel pump supplies sufficient fuel, under a constant pressure, to the injectors. These injectors inject metered quantity of fuel into the intake manifold in accordance with the signals from ECU. The engine ECU receives signals from various sensors indicating changing engine operating conditions such as:

- Crankshaft angle (G)

- $\quad$ Engine speed (NE)

- Acceleration/Deceleration (VTA)

- Coolant temperature (THW)

- Intake air temperature (THA)

These signals are utilized by the engine ECU to determine the injection duration necessary for the optimal air-fuel ratio to suit the present engine running conditions.

2. Electronic Spark Advance (ESA)

The engine ECU is programmed with data that will ensure optimal ignition timing under any and all operating conditions. Based on this data and on data provided by the sensors that monitor various engine operating conditions such as crankshaft angle, engine speed, coolant temperature etc. the engine ECU sends IGT (ignition timing) signals to the igniter to trigger the spark at precisely the right instant.

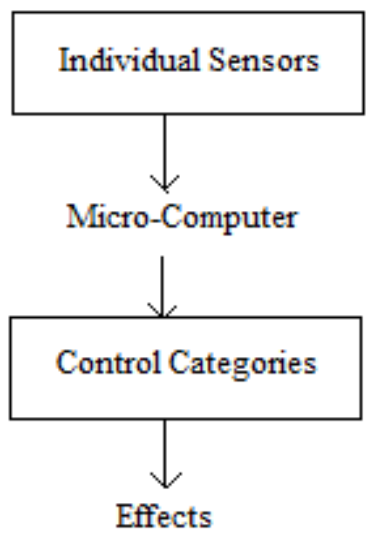

Figure 16: TCCS System Schematic

3. Idle Speed Control (ISC)

The engine ECU is programmed with target engine speed values to respond to different engine condition. Sensors transmit signals to the engine ECU, which by means of the throttle valve bypass and adjust he idle speed to the target value.

4. Diagnostic Function

The engine ECU is constantly monitoring the signals that are input $t$ it from the various sensors. If it detects any malfunctions in the input signals, the engine ECU stores data on the malfunction in its memory and lights the 'Check Engine' lamp.

5. Fail-Safe function 


\section{International Journal of Engineering Applied Sciences and Technology, 2019 \\ Vol. 4, Issue 6, ISSN No. 2455-2143, Pages 163-176 \\ Published Online October 2019 in IJEAST (http://www.ijeast.com)}

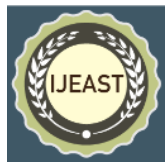

If the signals input to the engine ECU are abnormal, the engine ECU switches to standard values stored in its internal memory to control the engine. This makes it possible to control the engine so as to continue more or less normal vehicle operation.

\section{Back-Up Function}

Even if the engine ECU itself becomes partially inoperative, the back-up function can continue to execute fuel injection and ignition timing control. This makes it possible to control the engine so as to continue more or less vehicle operation.

7. Other Control Systems

In some engines, the OD cut-off control system, intake air control system and some other auxiliary systems are also controlled by the engine ECU.

The basic architecture of a TCCS system consists of items detected by individual sensors, a micro-computer, control categories and effects. Items detected by individual sensors include throttle position, coolant temperature, intake air volume engine revolutions, air-fuel ratio, air conditioner ON/OFF, vehicle speed, ECT mode selection, starter operation and brake operation [24]. Control categories include fuel injection, injection timing, idling speed, shift points cutch lock up and diagnostics. Effects are mainly improved performance, improved fuel efficiency, improved comfort, improved service ability etc.

\section{CONCLUSION}

Reputed firms in U.S.A., Europe and Japan have developed many basic systems of electronic fuel management and automatic transmission with wide variations in approach and systems. The three basic areas of development are sensors, signal processing units and actuators. The electronic controls using signal processing circuits, A/D converters, microprocessors and D/A converters are within the manufacturing capabilities of various firms in the country. A detailed study of interfacing precision sensors to convert mechanical parameters to electrical signals and actuators to drive fuel racks, valve, gear and electro hydraulic propulsion valves has to be made with the help of engine sensitivity functions. Most sensors and actuators have to be imported. The functions made possible by electronics are now integral to the mechanical concepts of new designs. Also, it is important to remember that most vehicle systems utilizing electronics have mechanical inputs and outputs and in most cases mechanical engineers have the systems responsibility. Therefore, it is essential that the automotive system designer familiarize himself with the advantages of electronic control systems. The various system components and their applications to electronic control are paving the way for more powerful vehicles with considerable fuel economy, ride comfort and safety.

\section{ACKNOWLEDGMENT}

We thank Dr. Ajay Babu (Asst. Professor, NSS College of Engineering Palakkad, Kerala, India) for the help in this manuscript and my frie for the help in research and development of the manuscript.

\section{REFERENCES}

[1] Weiwei Mao, Yunsheng Lu, R. K. Gulati and R. Dandapani, "Test generation for linear analog circuits," Proceedings of the IEEE 1995 Custom Integrated Circuits Conference, Santa Clara, CA, USA, 1995 , pp. 521-524.

[2] "A 32-KB Standard CMOS Antifuse One-Time Programmable ROM Embedded in a 16-bit Microcontroller," in IEEE Journal of Solid-State Circuits, vol. 41, no. 9, pp. 2115-2124, Sept. 2006.

[3] S. Ramy, A. Hatem and A. Mami, "Study and design of a power management system using two-stage controller for PEM fuel cell vehicles," 2016 7th International Renewable Energy Congress (IREC), Hammamet, 2016, pp. 1-6.

[4] E. V. Vijay, C. V. R. Rao, E. V. Kumar and G. N. Swamy, "Electronic control unit for an adaptive cruise control system \& engine management system in a vehicle using electronic fuel injection," INTERACT2010, Chennai, 2010, pp. 143-146.

[5] B. M. De Alcântara Dias, A. A. M. Laganá, J. F. Justo, L. R. Yoshioka, M. M. D. Santos and Z. Gu, "ModelBased Development of an Engine Control Module for a Spark Ignition Engine," in IEEE Access, vol. 6, pp. 53638-53649, 2018.

[6] Zhang Xin and Cai Ling, "Study of integrative performance test system for the automobile engine control unit," 2011 International Conference on Electric Information and Control Engineering, Wuhan, 2011, pp. 4495-4498.

[7] L. Schöning and Yun Li, "Review electromagnetic field ignition system for Internal Combustion Engine," The 17th International Conference on Automation and Computing, Huddersfield, 2011, pp. 306-309

[8] L. Zhenyong, C. Xin and R. Shiwei, "Study on Monitoring and Fault Diagnosis for Ignition System of Engines," 2009 First International Workshop on Education Technology and Computer Science, Wuhan, Hubei, 2009, pp. 895-899.

[9] E. V. Vijay, C. V. R. Rao, E. V. Kumar and G. N. Swamy, "Electronic control unit for an adaptive cruise control system \& engine management system in a vehicle using electronic fuel injection," INTERACT2010, Chennai, 2010, pp. 143-146.

[10] Z. Dai, P. Dong and W. Guo, "Adaption strategy of power on down shift for automatic transmission," 2016 35th Chinese Control Conference (CCC), Chengdu, 2016, pp. 9005-9009.

[11] M. Venturi, C. Mohrdieck and J. Friedrich, "MercedesBenz E-Class Fuel Cell: The world largest hydrogen vehicle fuel cell fleet experience," 2013 World Electric Vehicle Symposium and Exhibition (EVS27), Barcelona, 2013, pp. 1-11.

[12] J. Voelcker, "The Soul Of A New Mercedes," in IEEE Spectrum, vol. 45, no. 12, pp. 36-41, Dec. 2008. doi: 10.1109/MSPEC.2008.4687367

[13] Bert Breuer; Uwe Dausend, "11 SBC - The ElectroHydraulic Brake System from Mercedes-Benz," in Advanced Brake Technology, , SAE, 2003, pp.183203

[14] X. Lu, Z. Zhou and Y. Wang, "Design and comparative study of ABS control strategies based on cosimulation," 2015 IEEE International Conference on Cyber Technology in Automation, Control, and 
Intelligent Systems (CYBER), Shenyang, 2015, pp. 1665-1670.

[15] Soni. L.. Domala. D. and Venkateswaran. S.. 2019. Combi Brake Svstem (CBS) desion and tuning on an electric two wheeler for cornering maneuver (No. 2019-28-2399). SAE Technical Paper.

[16] 7öhel. Dieter. David Polock. and Philinn Woike. "Steering assistance for backing un articulated vehicles." Svstemics, Cybernetics and Informatics 1.5 (2003): 101-106.

[17] A. G. THOMPSON (1976) An Active Susnension with Ontimal I inear State Feedback, Vehicle System Dvnamics. 5:4, 187203, DOI: $10.1080 / 00423117608968414$

[18] K. C. Wei and G. A. Dage, "An intelligent automotive climate control system," 1995 IEEE International Conference on Systems, Man and Cybernetics. Intelligent Systems for the 21st Century, Vancouver, BC, Canada, 1995, pp. 2977-2982 vol.4.

[19] Ashlev. P. G. "Fuses and fusible cut-outs." .Journal of the Institution of Electrical Engineers 63, no. 347 (1925): 1133-1137.

[20] Lee. C.. Jeon. Y. and No. K.. 2003. Lithium niobate electro-ontic sensor for examining conductive natterns on display panels. Optical Engineering, 42, pp.15891596.

[21] Rohertson. I. S. (1975). Safetv helt use in automohiles with starter-interlock and buzzer-light reminder svstems. American Journal of Public Health, 65(12), 1319-1325.

[22] Robertson. L. S. (1975). Factors associated with safetv helt use in 1974 starter-interlock enuinned cars. Journal of Health and Social Behavior, 173-177.

[23] Sagberg. F.. Fosser. S. and Sætermo. I.A.F.. 1997. An investigation of hehavioural adantation to airhags and antilock brakes among taxi drivers. Accident Analysis \& Prevention, 29(3), pp.293-302.

[24] Taga. Yutaka. Ka7umasa Nakamura. Hiroshi Ito. and Takao Taniguchi. Tovota Commuter Controlled FourSneed Automatic Transmission. No. 820740. SAE Technical Paper, 1982.

[25] Ciepka, Piotr. (2016). Effect of ABS and CBS on motorcycle braking deceleration on a wet road surface. Problems of Forensic Sciences. 107. 557-568.

[26] Nakavama. T. and F. Suda. "The nresent and future of electric nower steering." International Journal of Vehicle Design 15.3-5 (1994): 243-254.

[27] Badawv. Alv. et al. Modeling and analvsis of an electric nower steering system. No. 1999-01-0399. SAE Technical Paper, 1999.

[28] Krafcik. Iohn. "Sav Hello to Wavmo: What's Next for Google's Self-Driving Car Project." Medium. December 13 (2016). 